\title{
Effects of Clozapine on In Vitro Immune Parameters: A Longitudinal Study in Clozapine-Treated Schizophrenic Patients
}

\author{
Dunja Hinze-Selch, M.D., E. Wolfgang Becker, Ph.D., Gerburg M. Stein, Ph.D., \\ Peter A. Berg, M.D., Janet Mullington, Ph.D., Florian Holsboer, M.D., Ph.D., \\ and Thomas Pollmächer, M.D.
}

Clozapine is an atypical antipsychotic agent with immunomodulatory properties. We hypothesized that in vitro immune parameters of peripheral blood mononuclear cells (PBMC) are affected in the course of clozapine treatment and that clozapine per se, added in vitro to $P B M C$ cultures of clozapine-treated patients, exerts differential effects in the timecourse of treatment in vivo. We measured proliferation and cytokine secretion of PBMC, serum autoantibodies, and immunoglobulin levels in 17 patients before and during the first 6 weeks of clozapine treatment. Independent of clozapine dosage and rectal temperature, clozapine treatment in vivo suppressed proliferation and shedding of sIL-2r by PBMC, and the addition of clozapine in vitro induced, relative to unstimulated conditions, $P B M C$ proliferation and secretion of IL-6 and sIL-2r. Serum IgG levels were increased; whereas, autoantibody pattern was unaffected. Thus, clozapine treatment and the addition of clozapine in vitro exert differential effects on various in vitro immune parameters independent of clozapine dosage and rectal temperature in the course of treatment.

[Neuropsychopharmacology 19:114-122, 1998] (C) 1998 American College of Neuropsychopharmacology. Published by Elsevier Science Inc.
KEY WORDS: Clozapine; Lymphocyte transformation; Peripheral blood mononuclear cells; Cytokines;

Neuroleptics; Schizophrenia

Clozapine is an atypical antipsychotic agent (Baldessarini and Frankenburg 1991) with immunomodulatory properties. An involvement of the immune system has been discussed for several clozapine-induced side effects, such as transient fever (Blum and Mauruschat 1972; Pollmächer et al. 1996), agranulocytosis (Pisciotta

From the Max Planck Institute of Psychiatry, Clinical Institute (DHS, JM, FH, TP), Munich; and the Department of Internal Medicine (EWB, GMS, PAB), University of Tübingen, Tübingen, Germany.

Address correspondence to: Dunja Hinze-Selch, M.D., Max Planck Institute of Psychiatry, Clinical Institute, Kraepelinstrasse 10, D-80804 Munich, Germany.

Received May 29, 1997; revised October 29, 1997; accepted December 31, 1997. and Konings 1994), coagulopathies (Davis et al. 1994) and parotitis (Hinze-Selch et al. 1996). Independent of such side effects, clozapine treatment consistently increases the plasma levels of cytokines and soluble cytokine receptors that are pivotal immune mediators. In particular, there are consistent reports on increases in the plasma levels of tumor necrosis factor- $\alpha$ (TNF- $\alpha$ ), soluble TNF-receptor p55 (TNF-Rp55), TNF-Rp75 and soluble interleukin-2 receptor (Maes et al. 1994; Pollmächer et al. 1995; Pollmächer et al. 1996). These effects were already evident after the first week of treatment and persisted for at least 6 weeks (Pollmächer et al. 1996). Clozapine-induced fever was accompanied by more pronounced increases in TNF- $\alpha$ plasma levels as well as by increases in the plasma levels of IL-6 and granulocyte colony-stimulating factor (G-CSF) and in granulocyte counts (Pollmächer et al. 1996; Pollmächer et al. 1997). 
The only study investigating cytokine secretion in vitro (Sperner-Unterweger et al. 1993) reported a significant suppression of the in vitro clozapine-stimulated secretion of granulocyte-macrophage colony-stimulating factor (GM-CSF) by peripheral blood mononuclear cells (PBMC) of clozapine-treated patients and untreated controls in a cross-sectional approach. The same trend of suppressive activity was described for the in vitro clozapine-initiated proliferative response of PBMC (Sperner-Unterweger et al. 1993); whereas, no effect on the mitogen-stimulated proliferation was found in another cross-sectional study (Rapaport et al. 1990). This still incomplete puzzle of data suggests that clozapine has effects on different in vivo and in vitro immune parameters depending upon the variable assessed and possibly on the time point during clozapine treatment. We hypothesized that in vitro immune parameters of PBMC are affected in the course of clozapine treatment and that clozapine, per se, added in vitro to PBMC cultures of clozapine-treated patients, exerts differential effects on the immunological function of these cells depending upon the time point of clozapine treatment in vivo.

Therefore, in a 6-week longitudinal study, we investigated the effect of clozapine treatment as well as the effect of clozapine added to in vitro PBMC cultures on various immune parameters of 17 schizophrenic patients. We analyzed the in vitro clozapine and, as a control for maximum stimulation, the mitogen-stimulated secretion of sIL-2r, IL-6, TNF- $\alpha$, and IL-2. We performed proliferation assays as lymphocyte transformation tests (LTT) with PBMC in response to clozapine at different in-vitro concentrations, ranging from normal plasma concentrations to 1,000-fold concentrations and, as a control, in response to pokeweed mitogen (PWM). In addition, we analyzed serum samples for a panel of autoantibodies and for IgG, $\operatorname{IgA}$, and $\operatorname{IgM}$ concentrations.

\section{METHODS}

\section{Patients}

Seventeen psychiatric inpatients ( 8 males, 9 females; mean age $31.4 \pm 6.7$ years, range $20-42$ years) meeting diagnostic criteria for a schizophrenic disorder according to DSM-III-R (American Psychiatric Association 1987) gave written informed consent before participating in the investigation, which had been approved by an independent ethics committee. None of the patients met diagnostic criteria for alcohol or substance abuse during the preceding 6 months. All of the patients had shown an insufficient antipsychotic response or had experienced intolerable side effects when treated with classic neuroleptics. These 17 patients are a subgroup of the patients included in our study on the effects of cloz- apine treatment on the plasma levels of cytokines and soluble cytokine receptors (Pollmächer et al. 1996).

Physical examination, medical history, and baseline laboratory investigations (white blood cell counts, differential count, red blood cell count, creatinine, electrolytes, GOT, GPT, AP, $\gamma \mathrm{GT}$, Quick, partial thromboplastin time, serum electrophoresis, blood sedimentation rate, $C$ reactive protein, serum iron, transferrin, glucose, thyroid-stimulating hormone) did not reveal acute or chronic inflammation and infection or autoimmunological, endocrine, and hematological diseases. None of the patients had been treated with clozapine during the 6 months before enrollment in the study. Eight patients had not received any psychopharmacological treatment during that period, and nine had haloperidol, perazine, flupenthixol, biperiden, promethazine, or lorazepam. These substances were withdrawn within the first 2 weeks of clozapine treatment. Following the initial evaluation, clozapine treatment was started, and the dosage was adjusted according to clinical needs. White blood cell and differential counts were performed weekly. Patients experiencing fever were screened for infection by medical history, physical examination, and laboratory investigations (the baseline set-up) and, if infection was suspected, urine culture for bacteria, throat swab, blood culture, and serological investigations were done. Blood was drawn and rectal temperature was measured between 0800 and 0900 hours. Leukocyte, granulocyte, lymphocyte, and monocyte counts were assessed with a Coulter Counter (Counter ST3, Coulter Inc., Krefeld, Germany).

\section{Cell Preparation and in vitro Assays}

$20 \mathrm{ml}$ of heparinized blood was used for the PBMC preparation, and $5 \mathrm{ml}$ of blood was taken for the autoantibody analysis in serum. Cell preparation and in vitro proliferation assays are described in detail elsewhere (Berg and Becker 1995). Briefly, human PBMC were separated by Ficoll density gradient centrifugation, washed two times with Hank's balanced salt solution and suspended in a synthetic culture medium at $3 \times$ $10^{6}$ cells per $\mathrm{ml}$. The medium consisted of RPMI 1640 FG (Biochrom, Berlin, Germany), supplemented with gentamicin $(100 \mu \mathrm{g} / \mathrm{ml}) .100 \mu \mathrm{l}$ of the cell suspension, $50 \mu \mathrm{l}$ of autologous plasma, and $50 \mu \mathrm{l}$ of the test solution were dispensed in quintuplicates into flat-bottomed 96-well plates (NUNC, Wiesbaden, Germany). The clozapine concentrations tested were 0.1, 1.0, 10, 100 , and $1,000 \mu \mathrm{g} / \mathrm{ml}$. The cells were incubated for 7 days at $37^{\circ} \mathrm{C}$ in a humidified atmosphere containing $5 \%$ $\mathrm{CO}_{2}$. Eighteen hours before termination of the test, 100 $\mu \mathrm{l} /$ well of the culture supernatants was aspirated and stored frozen $\left(-20^{\circ} \mathrm{C}\right)$. Cultures were then pulsed with $18.5 \mathrm{kBq}$ of tritiated thymidine per well (Amersham, Braunschweig, Germany). The cells were harvested 
onto fiberglass filters and measured as counts per minute (cpm) in a liquid scintillation counter (1205 Betaplate, Pharmacia, Germany). The stimulation index (SI) was calculated by dividing the mean of the cpm induced by the respective test solution in the experimental wells by the mean of the cpm of the medium control. PWM (Biochrome, Berlin) was used as a positive control at a concentration of $2.5 \mu \mathrm{g} / \mathrm{ml}$, which was shown to lead to maximum stimulation.

\section{Analysis of Cytokines in the Supernatants}

For evaluation of the effects of PWM, the supernatants of the cell cultures of all 17 patients were analyzed; whereas, for the spontaneous and in vitro clozapine-stimulated $(0.1,10,1,000 \mu \mathrm{g} / \mathrm{ml})$ set-up, the supernatants of only nine of the patients were analyzed. Cytokines were measured by enzyme-linked immunosorbent assays (ELISA; TNF- $\alpha$, IL- 6 and IL-2: Medgenix Diagnostics, Brussels, Belgium; sIL-2r: Biermann Diagnostics, Bad Nauheim, Germany). For all assays, the intra- and interassay coefficients of variation were below $8 \%$. Sensitivity for the detection of TNF- $\alpha$ and IL- 6 was $3 \mathrm{pg} / \mathrm{ml}$, for the detection of sIL-2r $2 \mathrm{IU} / \mathrm{ml}$, and for the detection of IL-2 0.05 $\mathrm{IU} / \mathrm{ml}$. Supernatant samples were appropriately diluted with the respective assay buffer, and each sample was measured in two dilutions.

\section{Detection of Autoantibodies}

Organ-Specific Autoantibodies. Patients' sera were tested by an immunofluorescence test (IFL) on cryostat sections from rat liver, kidney, stomach, and heart and human thyroid as well as on cell cultures using Chang (human hepatoma) cells, HeLa (human cervix carcinoma) cells and BHK (baby hamster kidney) cells and standard protocols (Klein and Berg 1994).

Other Autoantibodies. For the detection of antibodies to serotonin, gangliosides, phospholipids, and central nervous system tissue by ELISA, a standard method was applied (Engvall 1980), modified as recently described (Klein and Berg 1994). Serotonin (Sigma, St. Louis, Missouri, USA) and gangliosides (Gm1; Boehringer, Mannheim, Germany) were used at a concentration of $10 \mu \mathrm{g} / \mathrm{ml}$. Antibodies to phospholipids were detected by using rabbit thromboplastin (50 $\mu \mathrm{g} / \mathrm{ml}$; Sigma). For the detection of antibodies against central nervous system tissue (anti-CNS) synaptic and nonsynaptic mitochondria and microsomes were prepared from bovine brain (Lai and Clark 1979) and used at a concentration of $10 \mu \mathrm{g} / \mathrm{ml}$. Optimal serum dilutions were 1:500 for serotonin, 1:1,000 for gangliosides, 1:200 for phospholipids and 1:1,000 for CNS. Monovalent peroxidase-conjugated antihuman IgG (Fab2 fragments) and antihuman IgM antibodies from goat (Di- anova, Hamburg, Germany) were used at a dilution of $1: 3,000$. As standards, sera with high, medium, and low antibody titres as well as negative sera were employed for the detection of each antibody.

\section{Statistics}

To approach homogeneity in the variances within the various experimental conditions, the proliferation and cytokine secretion data were logarithmized before their statistical evaluation. For testing the effect of the in-vitro manipulations and the effect of time on the transformed data multivariate analysis of variance (MANOVA) with repeated measures designs was applied. Thereby clozapine-in-vitro-concentrations and time were two withinsubjects factors with six concentration levels for the proliferation data and four concentration levels for the cytokine secretion data and four time levels for proliferation as well as cytokine secretion data, respectively. The time effect on the PWM-stimulated proliferation and cytokine secretion data as well as on clozapine dosage, and the blood cell counts was tested about significance by one-factorial MANOVA with time as the one within-subjects factor with four levels. When significant main or interaction effects were found, univariate $F$-tests were applied to identify the variables contributing significantly to these effects. For these variables, tests with contrasts were performed to localize the pairs of clozapine in vitro concentrations or time levels that showed significant differences in the means of the variables. To separate possible effects on the proliferation and cytokine data from eventual effects of rectal temperature and clozapine dosage, the last two variables were considered as covariates in MANOVA. For estimating an effect of psychotropic premedication, the status of premedication was considered as a between-subjects factor in a separate design in MANOVA. Differences in the serum immunoglobulin levels were tested for significance by a one-factorial MANOVA with rectal temperature and clozapine dosage as covariates and with time as the one within-subjects factor with two levels; for estimating an effect of psychotropic premedication on serum immunoglobulin levels, the status of premedication was considered as a between-subjects factor in a separate design in MANOVA. Results are expressed and presented as means \pm standard deviation. As nominal level of significance $\alpha=0.05$ was accepted and corrected according to the Bonferroni procedure for all post hoc comparisons (univariate $F$-tests and tests with contrasts).

\section{RESULTS}

Analysis of variance revealed a significant time effect to which clozapine dosage contributed significantly with 
the major increments occurring during the first 2 weeks; the patients' leukocyte, granulocyte, lymphocyte, and monocyte counts were not significantly affected over time (Table 1). Eight patients developed a fever ranging from 38.0 to $39.7^{\circ} \mathrm{C}$ (mean rectal temperature $38.8^{\circ} \mathrm{C} \pm$ 1.0), starting between days 2 and 25 (mean $14.6 \pm 5.3$ ) and lasting for 1 to 6 days (mean duration 2.5 days \pm 1.3). In none of these patients, an infectious cause for the fever could be found.

The results of the proliferation assays are presented in Table 2. MANOVA revealed a marginally significant time effect on the proliferative response $(\mathrm{F}[3,7]=3.19$, $p=.09$ ) by means of suppressed spontaneous proliferation and suppressed proliferation in response to the clozapine in vitro concentrations of 1.0 and $100 \mu \mathrm{g} / \mathrm{ml}$ after the initiation of clozapine treatment; PWM-stimulated proliferation was unaffected. Clozapine at in vitro concentrations of 100 and $1000 \mu \mathrm{g} / \mathrm{ml}$ was toxic, resulting in suppression of the proliferative response already at baseline. The effect of the different nontoxic clozapine in vitro concentrations on proliferation reached statistical significance by MANOVA $(\mathrm{F}[5,5]=15.04, p=$ .005 ) and is demonstrated in Figure 1; the proliferative response is expressed relative to the respective spontaneous proliferation, which corresponds to the stimulation index. MANOVA with the effects of the nontoxic clozapine in vitro concentrations at each time point revealed a significant effect of these clozapine in vitro concentrations only at the end of weeks 1 and 2. Rectal temperature and clozapine dosage considered as covariates in MANOVA did not have a significant impact on these results, neither had the status of premedication as assessed as a between-subjects factor by a separate design in MANOVA.

Cytokine secretion of PBMC was analyzed after addition of clozapine at in vitro concentrations of $0,0.1$, 10 , and $1,000 \mu \mathrm{g} / \mathrm{ml}$ or of PWM as a control (Table 3). PWM-stimulated secretion of all the cytokines mea- sured was not significantly affected in the timecourse of clozapine treatment. However, MANOVA with the effect of time on spontaneous and clozapine-stimulated secretion showed a clear statistical trend of suppressed levels of sIL-2r after the initiation of clozapine treatment $(F[3,5]=4.6, p=.06)$. MANOVA with the effect of the different clozapine in vitro concentrations revealed significant changes for sIL-2r $(\mathrm{F}[3,5]=5.4, p=.05)$ and IL-6 $(\mathrm{F}[3,8]=15.8, p=.001)$. The addition of $0.1 \mu \mathrm{g} / \mathrm{ml}$ clozapine in vitro significantly increased secretion of both cytokines at all time points; whereas, the addition of 10 and 1,000 $\mu \mathrm{g} / \mathrm{ml}$ suppressed secretion of IL- 6 at all timepoints and showed variable effects on the levels of sIL-2r. The stimulatory and suppressing effects of the different clozapine in vitro concentrations applied, and slight trends toward suppression of cytokine secretion after the initiation of clozapine treatment were similar for IL-2 and TNF- $\alpha$; however, without reaching statistical significance. Again, rectal temperature and clozapine dosage considered as covariates in MANOVA did not affect these results, nor did the status of premedication as assessed as a between-subjects factor by a separate design in MANOVA.

Table 4 gives the number of patients in whose serum the respective autoantibodies were detected at baseline and at the end of week 6 . Of the 15 autoantibodies screened for, only six were detected in our patients at baseline and eight at the end of week 6 . There was no systematic induction or inhibition of any of the autoantibodies. Except for the antikeratin and antismooth muscle autoantibodies, with a slight preponderance in the patients with clozapine-induced fever, the conditions of psychopharmacological pretreatment and clozapine-induced fever did not systematically affect the autoantibody pattern.

Serum concentrations of IgG increased significantly between baseline and the end of week 6; whereas, there was no significant effect on $\operatorname{Ig} \mathrm{A}$ and $\operatorname{IgM}$, as can also be

Table 1. Time Effects on Clozapine Dosage and Blood Cell Counts, $n=17$

\begin{tabular}{|c|c|c|c|c|c|c|}
\hline & \multicolumn{4}{|c|}{ Mean $\pm S D$} & \multicolumn{2}{|l|}{ MANOVA } \\
\hline & Baseline & Week 1 & Week 2 & Week 6 & $\mathbf{F}$ & $\mathrm{p}$ \\
\hline $\begin{array}{l}\text { Clozapine } \\
\text { dosage } \\
\text { (mg/day) }\end{array}$ & - & $178 \pm 57$ & $281 \pm 111^{a}$ & $325 \pm 152^{a}$ & $\mathrm{~F}(2,32)=10.00$ & $a$ \\
\hline $\begin{array}{l}\text { Leukocytes } \\
\quad\left(\times 10^{9} / \mathrm{ml}\right) \\
\text { Granulocytes }\end{array}$ & $6.6 \pm 1.7$ & $7.0 \pm 2.5$ & $7.4 \pm 2.3$ & $6.5 \pm 1.0$ & $\mathrm{~F}(3,48)=1.00$ & ns \\
\hline $\begin{array}{c}\left(\times 10^{9} / \mathrm{ml}\right) \\
\text { Lymphocytes }\end{array}$ & $4.4 \pm 1.6$ & $4.7 \pm 2.4$ & $5.2 \pm 2.3$ & $4.2 \pm 1.8$ & $\mathrm{~F}(3,48)=1.00$ & ns \\
\hline $\begin{array}{l}\left(\times 10^{9} / \mathrm{ml}\right) \\
\text { Monocytes }\end{array}$ & $1.9 \pm 0.4$ & $1.9 \pm 0.5$ & $1.8 \pm 0.4$ & $1.9 \pm 0.4$ & $\mathrm{~F}(3,48)=0.60$ & ns \\
\hline$\left(\times 10^{9} / \mathrm{ml}\right)$ & $0.3 \pm 0.2$ & $0.4 \pm 0.2$ & $0.4 \pm 0.2$ & $0.4 \pm 0.2$ & $\mathrm{~F}(3,48)=1.70$ & ns \\
\hline
\end{tabular}

${ }^{a}$ Denotes statistically significant time effects or differences between week 1 and the corresponding time point at the corrected level of significance (tests with contrasts in MANOVA; $p<.05$ ). 
Table 2. In vitro Clozapine- and Mitogen-Induced Proliferation of PBMC in Counts per Minute, $n=17$

\begin{tabular}{|c|c|c|c|c|c|c|}
\hline \multirow{2}{*}{$\begin{array}{l}\text { In vitro } \\
\text { Stimulation } \\
\text { by Clozapine } \\
(\mu \mathrm{g} / \mathrm{ml})\end{array}$} & \multirow[b]{2}{*}{ Baseline } & \multirow[b]{2}{*}{ Week 1} & \multirow[b]{2}{*}{ Week 2} & \multirow[b]{2}{*}{ Week 6} & \multicolumn{2}{|c|}{ MANOVA } \\
\hline & & & & & $F(1,14)$ & p \\
\hline 0.0 & $1975 \pm 3494$ & $393 \pm 366^{+}$ & $354 \pm 210^{+}$ & $339 \pm 243^{+}$ & 2.7 & + \\
\hline 0.1 & $939 \pm 1251$ & $343 \pm 279$ & $317 \pm 140$ & $509 \pm 488$ & 1.6 & ns \\
\hline 1.0 & $1863 \pm 3168$ & $515 \pm 533^{+}$ & $438 \pm 258^{+}$ & $360 \pm 297^{+}$ & 2.5 & + \\
\hline 10 & $1757 \pm 4085$ & $510 \pm 534$ & $438 \pm 322$ & $425 \pm 354$ & 0.8 & ns \\
\hline 100 & $170 \pm 49$ & $161 \pm 64^{+}$ & $128 \pm 51^{+}$ & $140 \pm 72^{+}$ & 2.5 & + \\
\hline 1,000 & $249 \pm 140$ & $219 \pm 192$ & $217 \pm 171$ & $181 \pm 131$ & 0.6 & ns \\
\hline PWM & $35,860 \pm 21,055$ & $28,726 \pm 19,912$ & $37,192 \pm 17,267$ & $32,356 \pm 25,039$ & 1.3 & ns \\
\hline
\end{tabular}

${ }^{+}$Denotes marginally significant time effects or differences of proliferation between baseline and the corresponding time point (tests with contrasts in MANOVA).

seen in Table 4. Rectal temperature and clozapine dosage considered as covariates in MANOVA did not affect these results, nor did the status of premedication as assessed as a between-subjects factor by a separate design in MANOVA.

\section{DISCUSSION}

This is the first systematic longitudinal investigation of in vitro immune parameters and autoantibody patterns in clozapine-treated patients. Clozapine treatment did not induce a panel of common autoantibodies in our patients in the course of 6 weeks, in particular it did not induce autoantibodies against thromboplastin, which had been reported in a patient with clozapine-associated coagulopathy (Davis et al. 1994). Autoantibodies against gangliosides, CNS tissue, and cell nuclei for which increased prevalences in schizophrenic patients were reported (Chengappa et al. 1992; Chengappa et al. 1995; Ganguli et al. 1992; Henneberg et al. 1994; LevySoussan et al. 1994; Stevens and Weller 1992) were not present at all, neither at baseline nor after 6 weeks of clozapine treatment. However, because all of our patients were refractory to treatment with classic neuroleptics, our data fit well with the study of Levy-Soussan and colleagues (1994), who reported that the prevalence of autoantibodies is lower in patients who do not respond to classic neuroleptics.

With respect to humoral aspects of immunity, we found that IgG serum levels, but not IgM or IgA serum levels, were significantly elevated at the end of week 6 . Thus, it is unlikely that clozapine treatment induces a classic specific humoral immune response via IgM. In addition, at least in this short period of 6 weeks, we did not observe cytotoxic phenomena suggestive of cytotoxic autoimmunologically active $\operatorname{IgM}$ factors as described for other immunoactive psychoactive substances such as chlorpromazine (Canoso et al. 1990) and in some patients with clozapine-induced agranulocytosis (Pisciotta and Konings 1994). Considering the lack of hematological side effects in our patients and the limited period of investigation, our findings are in agreement with the study of McAllister and colleagues (1989), who reported no effect of clozapine treatment on CD5-positive autoimmune B lymphocytes in clozapine-treated patients and concluded that clozapine does not induce a state of autoimmunity.

Our results on PBMC proliferation and cytokine secretion suggest that, if clozapine treatment of the patients has an effect on these in vitro parameters, this ef-

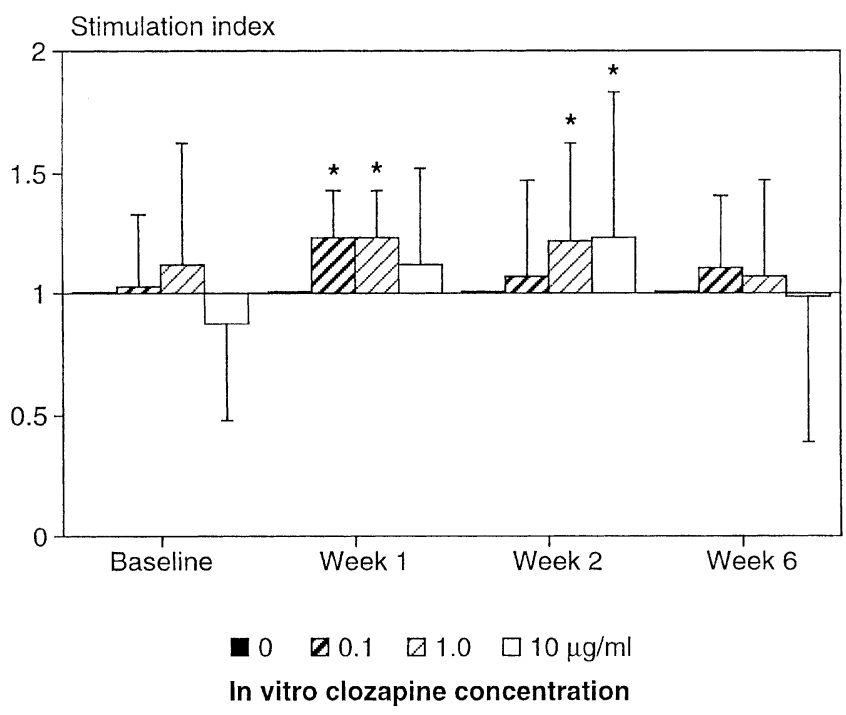

Figure 1. Spontaneous and clozapine-induced proliferation of PBMC. The time points when significant differences emerged were identified by univariate $F$-tests in MANOVA for Baseline $(\mathrm{F}[1,14]=1.7, p=.21)$, Week $1(\mathrm{~F}[1,14]=6.8$, $p=.007)$, Week $2(\mathrm{~F}[1,14]=4.8, p=.02)$, Week $6(\mathrm{~F}[1,14]=$ $1.6, p=.24)$. ${ }^{*}$ Denotes statistical significance of differences between spontaneous and the corresponding clozapine in vitro concentration-induced proliferation at the corrected level of significance (tests with contrasts in MANOVA; $p<$ .05). Stimulation index $=$ clozapine-induced proliferation $/$ spontaneous proliferation. 
Table 3. Spontaneous $(n=9)$, Clozapine- $(n=9)$ and PWM-Stimulated $(n=17)$ Cytokine Secretion of PBMC

\begin{tabular}{|c|c|c|c|c|c|}
\hline & Baseline & Week 1 & Week 2 & Week 6 & $\begin{array}{l}\text { MANOVA } \\
\text { F(1,9)/p }\end{array}$ \\
\hline \multicolumn{6}{|c|}{ IL-6 (pg/ml) } \\
\hline PWM & $25231 \pm 16925$ & $27949 \pm 13881$ & $32122 \pm 19529$ & $29358 \pm 16362$ & $0.1 / \mathrm{ns}$ \\
\hline $\begin{array}{l}0 \\
0.1 \quad(\mu \mathrm{g} / \mathrm{ml} \\
10 \quad \text { clozapine }) \\
1000\end{array}$ & $\begin{aligned} 64 & \pm 99 \\
216 & \pm 206^{*} \\
43 & \pm 83^{*} \\
14 & \pm 33^{*}\end{aligned}$ & $\begin{aligned} 107 & \pm 200 \\
237 & \pm 188^{+} \\
73 & \pm 175^{+} \\
58 & \pm 170^{+}\end{aligned}$ & $\begin{array}{c}203 \pm 356 \\
312 \pm 254^{*} \\
129 \pm 224^{*} \\
14 \pm 10^{*}\end{array}$ & $\begin{aligned} 157 & \pm 396 \\
274 & \pm 207^{*} \\
94 & \pm 174^{*} \\
31 & \pm 46^{*}\end{aligned}$ & $\begin{array}{l}1.2 / \mathrm{ns} \\
2.1 / \mathrm{ns} \\
0.9 / \mathrm{ns} \\
1.0 / \mathrm{ns}\end{array}$ \\
\hline $\begin{array}{l}\text { MANOVA,F }(1,9) \\
\mathrm{p}\end{array}$ & $\begin{array}{l}7.1 \\
*\end{array}$ & $\begin{array}{c}3.0 \\
+\end{array}$ & $\begin{array}{c}124.8 \\
*\end{array}$ & $\begin{array}{c}6.7 \\
*\end{array}$ & \\
\hline \multicolumn{6}{|c|}{ sIL-2r (IU/ml) } \\
\hline PWM & $8042 \pm 7703$ & $7472 \pm 5740$ & $9478 \pm 6702$ & $10143 \pm 5859$ & $1.4 / \mathrm{ns}$ \\
\hline $\begin{array}{l}0 \\
0.1 \quad(\mu \mathrm{g} / \mathrm{ml} \\
10 \quad \text { clozapine }) \\
1000\end{array}$ & $\begin{aligned} 237 & \pm 644 \\
277 & \pm 554^{+} \\
421 & \pm 1168^{+} \\
16 & \pm 23^{+}\end{aligned}$ & $\begin{array}{l}8.1 \pm 15 \\
22 \pm 28^{+} \\
6.8 \pm 11^{+\S} \\
6.4 \pm 14^{+}\end{array}$ & $\begin{array}{l}5.5 \pm 16 \\
30 \pm 24^{*} \\
1.8 \pm 4.9^{* \S} \\
5.0 \pm 9.1\end{array}$ & $\begin{array}{l}0.6 \pm 1.8 \\
31 \pm 34 \\
3.8 \pm 7.6^{\S} \\
8.3 \pm 15\end{array}$ & $\begin{array}{l}1.5 / \mathrm{ns} \\
1.6 / \mathrm{ns} \\
2.9 / \S \\
1.2 / \mathrm{ns}\end{array}$ \\
\hline $\begin{array}{l}\text { MANOVA,F }(1,9) \\
\mathrm{p}\end{array}$ & $\begin{array}{c}3.6 \\
+\end{array}$ & $\begin{array}{c}3.5 \\
+\end{array}$ & $\begin{array}{c}5.9 \\
*\end{array}$ & $\begin{array}{l}2.8 \\
\text { ns }\end{array}$ & \\
\hline \multicolumn{6}{|c|}{ IL-2 (IU/ml) } \\
\hline PWM & $40 \pm 68$ & $88 \pm 104$ & $80 \pm 116$ & $33 \pm 48$ & $0.8 / \mathrm{ns}$ \\
\hline $\begin{array}{l}0 \\
0.1 \quad(\mu \mathrm{g} / \mathrm{ml} \\
10 \quad \text { clozapine }) \\
1000\end{array}$ & $\begin{array}{l}0.11 \pm 0.15 \\
0.18 \pm 0.29 \\
0.11 \pm 0.21 \\
0.08 \pm 0.25\end{array}$ & $\begin{array}{l}0.06 \pm 0.10 \\
0.19 \pm 0.34 \\
0.04 \pm 0.07 \\
0.04 \pm 0.13\end{array}$ & $\begin{array}{l}0.03 \pm 0.05 \\
0.19 \pm 0.38 \\
0.10 \pm 0.15 \\
0.02 \pm 0.06\end{array}$ & $\begin{array}{c}0.06 \pm 0.09 \\
0.16 \pm 0.29 \\
0.09 \pm 0.21 \\
0.0 \pm 0.0\end{array}$ & $\begin{array}{l}2.8 / \mathrm{ns} \\
0.2 / \mathrm{ns} \\
1.2 / \mathrm{ns} \\
0.3 / \mathrm{ns}\end{array}$ \\
\hline $\begin{array}{l}\text { MANOVA,F }(1,9) \\
\mathrm{p}\end{array}$ & $\begin{array}{l}0.3 \\
\text { ns }\end{array}$ & $\begin{array}{l}3.0 \\
\text { ns }\end{array}$ & $\begin{array}{l}1.0 \\
\text { ns }\end{array}$ & $\begin{array}{l}1.2 \\
\text { ns }\end{array}$ & \\
\hline \multicolumn{6}{|c|}{ TNF- $\alpha(\mathrm{pg} / \mathrm{ml})$} \\
\hline PWM & $3304 \pm 1856$ & $2880 \pm 1310$ & $3546 \pm 1612$ & $3690 \pm 1760$ & $0.8 / \mathrm{ns}$ \\
\hline $\begin{array}{l}0 \\
0.1 \quad(\mu \mathrm{g} / \mathrm{ml} \\
10 \quad \text { clozapine }) \\
1000\end{array}$ & $\begin{array}{c}200 \pm 538 \\
198 \pm 454 \\
128 \pm 361 \\
0.0 \pm 0.0\end{array}$ & $\begin{array}{c}21 \pm 42 \\
27 \pm 51 \\
13 \pm 31 \\
0.0 \pm 0.0\end{array}$ & $\begin{array}{l}4.9 \pm 10 \\
7.4 \pm 14 \\
3.9 \pm 11 \\
0.0 \pm 0.0\end{array}$ & $\begin{array}{c}19 \pm 53 \\
35 \pm 91 \\
31 \pm 88 \\
0.0 \pm 0.0\end{array}$ & $\begin{array}{c}2.8 / \mathrm{ns} \\
1.1 / \mathrm{ns} \\
0.2 / \mathrm{ns} \\
\mathrm{ns}\end{array}$ \\
\hline $\begin{array}{l}\text { MANOVA,F(1,9) } \\
\mathrm{p}\end{array}$ & $\begin{array}{l}3.8 \\
\mathrm{~ns}\end{array}$ & $\begin{array}{l}1.0 \\
\text { ns }\end{array}$ & $\begin{array}{l}1.0 \\
\mathrm{~ns}\end{array}$ & $\begin{array}{l}1.3 \\
\text { ns }\end{array}$ & \\
\hline
\end{tabular}

* Denotes significant clozapine in vitro concentration effects or differences between spontaneous and the corresponding clozapine-induced cytokine secretion at the corrected level of significance (tests with contrasts in MANOVA, $p<.05$ ).

${ }^{\S}$ Denotes marginally significant time effects or differences between sIL-2r secretion at baseline and the corresponding time points (tests with contrasts in MANOVA).

${ }^{+}$Denotes marginally significant clozapine in vitro concentrations or differences between spontaneous and the corresponding clozapine-induced cytokine secretion (tests with contrasts in MANOVA).

fect is lasting at least 6 weeks and of suppressive nature; whereas, if clozapine per se added in vitro has an effect, this effect is transient during the first 2 weeks and of stimulatory nature. These effects are independent of clozapine dosage, increases in rectal temperature, and the status of premedication. As these changes were not seen when the cells were stimulated with the mitogen PWM as control for maximum stimulation, PWM seems to override these subtle clozapine-induced effects. This observation is in line with findings of Rapa- port and colleagues (1990), who analyzed mitogen-stimulated proliferation in patients on a stable clozapine dose for 17 to 60 days and did not find any differences to the baseline levels of the same patients not treated with clozapine. Results on mitogen-stimulated cytokine secretion in the course of clozapine treatment have not been published previously. Thus mitogen-stimulated PBMC proliferation does not only seem to override clozapine-induced effects but also to be independent of the initiation and duration of clozapine treatment. The 
Table 4. Autoantibody Pattern and Immunoglobulin Concentrations in Sera of Patients Before and 6 Weeks After the Initiation of Clozapine Treatment, $n=17$

\begin{tabular}{lll}
\hline & Baseline & Week 6 \\
\hline ANA & 0 & 0 \\
SMA & $1(0)[0]$ & $3(1)[0]$ \\
AEA & $1(0)[0]$ & $1(1)[0]$ \\
ASA & $3(0)[2]$ & $1(0)[1]$ \\
Sinusoids & 0 & $2(0)$ \\
Heart muscle & 0 & 0 \\
Parietal cells & $3(0)[0]$ & $2(0)[1]$ \\
Thyroid & 0 & $2(0)$ \\
Serotonin & 0 & $1(1)[0]$ \\
Thromboplastin & 0 & 0 \\
CNS & 0 & 0 \\
Gangliosides & 0 & 0 \\
Microsomes & 0 & 0 \\
Laminin & $1(1)[0]$ & 0 \\
Keratin & $3(1)[2]$ & $4(3)[2]$
\end{tabular}

Immunoglobulin Concentration in $\mathrm{mg} / \mathrm{dl}$

\begin{tabular}{lcc}
\hline IgG & $841 \pm 297$ & $1067 \pm 312^{*}$ \\
IgA & $295 \pm 433$ & $175 \pm 52$ \\
IgM & $97 \pm 49$ & $124 \pm 52$ \\
\hline
\end{tabular}

Number of patients positive for the respective autoantibody, (number of patients with clozapine-induced fever), [number of patients without psychotropic treatment within 6 months prior to the initiation of clozapine treatment].

ANA $=$ antinuclear antibodies, SMA $=$ antismooth muscle antibodies, $\mathrm{AEA}=$ antiendothelial antibodies, $\mathrm{ASA}=$ antisarkolemn antibodies.

* Denotes significant differences between baseline and week 6 (tests with contrasts in MANOVA; $p<.05$; MANOVA for time effects F[1,12] $=$ $5.6, p=.01$.

clozapine in vitro concentrations that affected PBMC proliferation and cytokine secretion ranged between 0 and $10 \mu \mathrm{g} / \mathrm{ml}$; concentrations of $100 \mu \mathrm{g} / \mathrm{ml}$ and more were toxic, independent of the timecourse of clozapine treatment in the patients. This is in line with the results of Sperner-Unterweger and colleagues (1993), who reported that a clozapine in vitro concentration of $30 \mu \mathrm{g} /$ $\mathrm{ml}$ led already to a more than $50 \%$ reduction in the proliferative response of PBMC in both clozapine-treated patients and untreated healthy controls. However, as serum concentrations achieved during clozapine treatment range from 0 to $1.0 \mu \mathrm{g} / \mathrm{ml}$ (Hasegawa et al. 1993, 1994), these toxic in vitro effects of clozapine are probably without clinical relevance.

In the 17 clozapine-treated patients who were investigated, we did not observe side effects, such as abnormalities of blood cell counts or even agranulocytosis, but in 9 of the 17 patients, we did observe clozapine-induced fever. However, statistical analysis did not reveal significant differences between fever-developing and nonfever-developing subjects. Because not all of the feverdeveloping patients were febrile the day blood was drawn for the in vitro investigations we cannot exclude that we missed an acute effect of fever in our statistical analysis. However, we can conclude from our results that fever-developing and nonfever-developing clozapine-treated patients do not show basic differences in the immunological parameters we investigated.

The status of psychotropic premedication did not influence our results, either. This is in line with a report that a 6-week haloperidol treatment did not significantly affect plasma levels of cytokines and soluble cytokine receptors (Pollmächer et al. 1997b). However, there are reports on altered immune functions in patients treated with classic antipsychotics (Maes et al. 1995), and we cannot exclude such effects on in vitro immune parameters in general.

On the other hand, the strength of our study is the longitudinal aspect and the investigation of spontaneous and clozapine in vitro induced proliferation and cytokine secretion, because mitogen-induced proliferation seems to override the subtle effects of clozapine. Based on our finding that at the end of weeks 1 and 2 clozapine in vitro concentrations of $0.1,1$, and $10 \mu \mathrm{g} / \mathrm{ml}$ slightly, but significantly, increased the stimulation index, we speculate that clozapine treatment in vivo alters the sensitivity of PBMC to clozapine. This is a transient effect, because at the end of week 6 , there was no longer any evidence of enhanced activity. Thus, SpernerUnterweger and colleagues (1993) may have missed this critical time period in their cross-sectional study, in which they found no effect of clozapine in vitro concentrations of $7.5 \mu \mathrm{g} / \mathrm{ml}$ and higher. Although the relationship between clozapine plasma and in vitro concentrations for PBMC is unknown, it is striking that the range of clozapine in vitro concentrations that significantly affected stimulation indices during the first 2 weeks is in the range of clozapine plasma levels reached in vivo (Hasegawa et al. 1993; Ackenheil 1989).

We found that the initiation of clozapine treatment and the addition of clozapine in vitro significantly affected the secretion of sIL-2r and IL-6; whereas, the secretion of TNF- $\alpha$ and IL-2 was unaltered. It was reported that the plasma levels of sIL-2r and TNF- $\alpha$ were significantly increased by clozapine treatment per se; whereas, IL-6 levels were only increased during clozapine-induced fever (Maes et al. 1994; Pollmächer et al. 1995, 1996). At first glance, these results do not seem to be compatible with our in vitro results. A possible explanation for these discrepancies is that the in vitro conditions chosen do not reflect completely the in vivo situation. Under the particular in vitro stimulatory conditions described, we investigated here the PBMC fraction of whole blood that does not comprise, for example, granulocytes. However, there is growing evidence that granulocytes secrete cytokines including TNF- $\alpha$ (for review see Lloyd and Oppenheim 1992) and metabolize clozapine (Uetrecht 1992). Therefore, further in vitro studies might also include these cells under appropriate in vitro conditions. 
In conclusion, in our sample of schizophrenic patients, clozapine treatment did affect in vitro PBMC immune parameters by suppressing spontaneous and clozapine-induced proliferation and levels of sIL-2r. The addition of clozapine in vitro led to a stimulation of proliferation and shedding of sIL-2r only during the first 2 weeks of clozapine treatment; whereas, over the whole 6 week timecourse, clozapine in vitro stimulated IL-6 secretion. Thus, clozapine treatment and the addition of clozapine in vitro exert differential effects on different in vitro immune parameters in the course of treatment. In a previous study (Pollmächer et al. 1997a), we reported increased plasma levels of G-CSF in patients with clozapine-induced granulocytosis and hypothesized that, if this G-CSF increase is not transient, it might indicate exhaustion of granulopoesis and, therefore, might even be predictive of granulocytopenia in the course of clozapine treatment. Similarly, on the basis of our in vitro data, we speculate here that, if the clozapine in vitro-induced increase of the stimulation index persists over the first 2 weeks of clozapine treatment, the patient might be more sensitive to challenges of the immune system and, thus, be more prone to developing such side effects as parotitis where an increased stimulation index was already described (Hinze-Selch et al. 1996). However, to test this speculation, a long-term follow-up investigation of a large number of patients in the timecourse of clozapine treatment is needed.

\section{ACKNOWLEDGMENT}

The authors thank Alexander Yassouridis, Ph.D. for his excellent and expert statistical assistance.

\section{REFERENCES}

Ackenheil M (1989): Clozapine-Pharmacokinetic investigations and biochemical effects in man. Psychopharmacology 99:S32-S37

American Psychiatric Association (1987): Diagnostic and Statistical Manual of Mental Disorders, 3rd ed rev. Washington, DC, American Psychiatric Press

Baldessarini RJ, Frankenburg FR (1991): Clozapine, a novel antipsychotic agent. N Engl J Med 324:746-754

Berg PA, Becker EW (1995): The lymphocyte transformation test-A debated method for the evaluation of drug allergic hepatic injury. J Hepatol 22:115-118

Blum A, Mauruschat W (1972): Temperaturanstiege und Bluteiweißveränderungen unter der Therapie mit Neuroleptika-unter besonderer Berücksichtigung des neuartigen Dibenzodiazepinderivates Clozapin. Pharmakopsychiatr 5:155-169

Canoso RT, de Oliviera RM, Nixon RA (1990): Neurolepticassociated autoantibodies-A prevalence study. Biol Psychiatry 27:863-870
Chengappa KN, Carpenter AB, Yang ZW, Brar JS, Rabin BS, Ganguli R (1992): Elevated IgG antihistone antibodies in a subgroup of medicated schizophrenic patients. Schizophr Res 7:49-54

Chengappa KN, Ganguli R, Yang ZW, Shurin G, Brar JS, Rabin BS (1995): Impaired mitogen (PHA) responsiveness and increased autoantibodies in Caucasian schizophrenic patients with the HLA B8/DR3 phenotype. Biol Psychiatry 37:546-549

Davis S, Kern HB, Asokan R (1994): Antiphospholipid antibodies associated with clozapine treatment. Am J Hematol 46:166-167

Engvall E (1980): Enzyme immunoassay ELISA and EMIT. Methods Enzymol 70:419-439

Ganguli R, Rabin BS, Brar JS (1992): Antinuclear and gastric parietal cell autoantibodies in schizophrenic patients. Biol Psychiatry 32:735-738

Hasegawa M, Cola PA, Meltzer HY (1994): Plasma clozapine and desmethylclozapine levels in clozapine-induced agranulocytosis. Neuropsychopharmacology 11:45-47

Hasegawa M, Gutierrez-Esteinou R, Way L, Meltzer HY (1993): Relationship between clinical efficacy and clozapine plasma levels in schizophrenia: Effect of smoking. J Clin Psychopharmacol 13:383-390

Henneberg AE, Horter S, Ruffert S (1994): Increased prevalence of antibrain antibodies in the sera from schizophrenic patients. Schizo Res 14:15-22

Hinze-Selch D, Becker EW, Stein G, Schreiber W, Pollmächer T (1996): Clozapine-induced parotitis: An immunological cause? Am J Psychiatry 153:840

Klein R, Berg PA (1994): A comparative study on antibodies to nucleoli and 5-hydroxytryptamine in patients with fibromyalgia syndrome and tryptophan-induced eosinophilia myalgia syndrome. Clin Invest 72:541-549

Lai JCK, Clark JB (1979): Preparation of synaptic and nonsynaptic mitochondria from mammalian brain. Methods Enzymol 55:51-60

Levy-Soussan P, Barbouche R, Poirier MF, Galinowski A, Loo H, Avrameas S (1994): A preliminary prospective study on natural autoantibodies and the response of untreated schizophrenic patients to neuroleptics. Biol Psychiatry 35:135-138

Lloyd AR, Oppenheim JJ (1992): Poly's lament: The neglected role of the polymorphonuclear neutrophil in the afferent limb of the immune response. Immunol Today 13:169-172

Maes M, Bosmans E, Calabrese J, Smith R, Meltzer HY (1995): Interleukin-2 and interleukin-6 in schizophrenia and mania: Effects of neuroleptics and mood stabilizers. J Psychiat Res 29:141-152

Maes M, Meltzer HY, Bosmans E (1994): Immune-inflammatory markers in schizophrenia: Comparison to normal controls and effects of clozapine. Acta Psychiatr Scand 89:346-351

McAllister CG, Rapaport MH, Pickar D, Paul SM (1989): Effects of short-term administration of antipsychotic drugs on lymphocyte subsets in schizophrenic patients. Arch Gen Psychiatry 46:956-957

Pisciotta AV, Konings SA (1994): ${ }^{51}$ Cr release assay of clozapine-induced cytotoxicity: Evidence for immunogenic mechanism. J Clin Psychiatry 55:143-148 
Pollmächer T, Fenzel T, Mullington J, Hinze-Selch D (1997a): The influence of clozapine treatment on plasma granulocyte colony-stimulating factor (G-CSF) levels. Pharmacopsychiatry 30:118-121

Pollmächer T, Hinze-Selch D, Fenzel T, Kraus T, Schuld A, Mullington J (1997b): Plasma levels of cytokines and soluble cytokine receptors during treatment with haloperidol. Am J Psychiatry 154:1763-1765

Pollmächer T, Hinze-Selch D, Mullington J (1996): Effects of clozapine on cytokines and soluble cytokine receptors. J Clin Psychopharmacol 16:403-409

Pollmächer T, Hinze-Selch D, Mullington J, Holsboer F (1995): Clozapine-induced increase in plasma levels of soluble interleukin-2 receptors. Arch Gen Psychiatry 52:877-878
Rapaport H, McAllister CG, Kirch DG, Pickar D (1990): The effect of typical and atypical neuroleptics on mitogeninduced T lymphocyte responsiveness. Biol Psychiatry 29:715-717

Sperner-Unterweger B, Gaggl S, Fleischhacker WW, Barnas C, Herold M, Geissler D (1993): Effects of clozapine on hematopoiesis and the cytokine system. Biol Psychiatry 34:536-543

Stevens A, Weller M (1992): Ganglioside antibodies in schizophrenia and major depression. Biol Psychiatry 32:727-730

Uetrecht JP (1992): Metabolism of clozapine by neutrophils-Possible implications for clozapine-induced agranulocytosis. Drug Safety 7:51-56 